\title{
An Exploration of Development of Construction Device for Ocean Engineering Equipment
}

\author{
Peng Tao ${ }^{1,2,3}$, Lin Zhongqin ${ }^{2,3}$, Yang Jianmin ${ }^{1,2,3}$, Liu Cungen ${ }^{1,2,3}$ \\ 1. State Key Laboratory of Ocean Engineering, Shanghai Jiao Tong University, Shanghai 200240, China \\ 2. Collaborative Innovation Center for Advanced Ship and Deep-Sea Exploration, Shanghai 200240, China \\ 3. China Strategy Institute of Ocean Engineering, Shanghai 200240, China
}

\begin{abstract}
With the developing of large scale and deep-water, performance of ocean engineering equipment has been improved rapidly. The offshore manufacturing industry faces with the complex manufacturing process, exacting working conditions, and high accuracy requirements. Manufacturing devices should to be refined, flexible, parallel in processing and measurement, need more breakthroughs in complete sets of equipment, control system and etc. And provide the support for the development of the construction capacity of ocean engineering equipment industry, achieve the fine, intelligent and green development in manufacturing process.
\end{abstract}

Key words: ocean engineering equipment; construction device; manufacturing technology

Received date: 20 June 2016; revised date: 5 July 2016

Author information: Peng Tao, Shanghai Jiao Tong University, senior engineer. His current research is in ocean engineering. E-mail: pengtao@stju. edu.cn

Funding program: CAE Major Advisory Project "Research on Promotion and Development Planning of China's Strategic Emerging Industries in the 13th Five-Year Plan Period" (No. 2014-ZD-7)

Chinese version: Strategic Study of CAE 2016, 18 (4): 109-112

Cited item: Peng Tao et al. An Exploration of Development of Construction Device for Ocean Engineering Equipment. Strategic Study of CAE, http://10.15302/J-SSCAE-2016.04.016 